\title{
PRÁTICAS IDENTITÁRIAS NO JORNAL ESCOLAR: A PRODUÇÃO DE TEXTO NO ENSINO FUNDAMENTAL
}

\author{
Vanessa Wendhausen Lima ${ }^{1}$
}

\begin{abstract}
Resumo: A produção de jornal escolar pode evidenciar uma série de influências sobre os textos dos estudantes, sejam estas do âmbito do discurso, sejam do âmbito da prática social, sem que uma seja apartada da outra. Um dos aspectos que pode ser encontrado nessas produções é a prática identitária de estudantes que demonstram em seus textos mais que apenas uma soma de códigos e informações sobre sua localidade. Assim, o objetivo deste trabalho é analisar características evidenciadas nos textos produzidos por estudantes de uma turma de correção de fluxo de uma escola do ensino fundamental de Tubarão/SC. Este trabalho se configura como um excerto da tese de doutorado da autora e teve como aporte teórico a Análise Crítica de Gênero (BONINI, 2011) que toma o discurso e o gênero como bases de análise não apenas do texto, mas também da prática social de forma geral. A metodologia utilizada foi a da pesquisa participante (DEMO, 2008) e foi realizada durante um ano letivo em uma turma que precisava passar por adequações escolares em função do ensino fundamental de 9 anos (2012), chamada de Correção de Fluxo. Os resultados mostram que esta produção de jornal escolar se apresentou como uma estratégia reveladora de práticas identitárias desses estudantes e, para além disso, de como o discurso circulava entre os textos e, sobretudo, no mundo desses alunos de ensino fundamental.
\end{abstract}

Palavras-chave: Práticas identitárias. Jornal Escolar. Discurso.

\section{IDENTITY PRACTICES AT SCHOOL NEWSPAPER: THE TEXT PRODUCTION IN ELEMENTARY SCHOOL}

Abstract: The production of the school newspaper can show a series of influences on the students' texts, whether they are within the scope of the discourse, or within the scope of social practice, without being separated from the other. One of the aspects that can be found in these productions is the identity practice of students who demonstrate in their texts more than just a sum of codes and information about their locality. Thus, the objective of this work is to analyze characteristics evidenced in the texts produced by students of a class of correction of flow of a primary school in Tubarão / SC. This work is an excerpt from the doctoral thesis of the author and had as theoretical contribution the Critical Analysis of Gender (BONINI, 2011) that takes the discourse and the gender as bases of analysis not

\footnotetext{
1 Doutora em Ciências da Linguagem, professora dos cursos de Design, Jornalismo e Publicidade e Propaganda da Faculdade Satc, Criciúma, Santa Catarina, Brasil. E-mail: vanessa.wendhause.n@satc.edu.br.
} 
only of the text, but also of the social practice of general form. The methodology used was that of the participant research (DEMO, 2008) and was carried out during a school year in a class that had to undergo school adjustments due to 9-year elementary education (2012), called Flow strategy of the identity practices of these students and, moreover, of how the discourse circulated between texts and, especially, in the world of these elementary students.

Keywords: Identity Practices. School Newspaper. Discourse.

\section{Introdução}

O ensino de Língua Portuguesa pautado nos Parâmetros Curriculares Nacionais (PCNs) deve estar muito mais ligado a um ensino que saia dos livros didáticos e que demonstre como sobreviver em um mundo real. Dizer isso não significa dizer que os livros didáticos estão inadequados à realidade do mundo em que vivemos, no entanto, é possível estabelecer conexões firmes entre os conteúdos elencados nos livros didáticos utilizados nas escolas públicas e os processos seletivos das grandes universidades, ou seja, o estudante ideal é aquele que termina o ensino médio e se dedica a ingressar em uma universidade. Entretanto, a realidade dos estudantes de escola pública está muito distante desse ideal de vida pós período escolar.

Com base nessas ideias, a produção de jornal escolar analisada neste trabalho, visou permitir que os estudantes assumissem um papel autoral tanto no que se refere ao seu próprio processo de ensino e aprendizagem quanto à produção de conteúdo que pautava esse processo como um todo. Dessa forma, os estudantes estariam escrevendo textos que poderiam mostrar suas realidades e, ao mesmo tempo, poderiam desenvolver um potencial de escrita que seria evidenciado entre os colegas e a comunidade escolar como um todo. Lembro que este é um excerto da tese de doutorado da autora, defendida em 2014, na Universidade do Sul de Santa Catarina.

\section{A Análise Crítica de Gênero}

Segundo Lima (2014), contrariando a tradição de análise de gêneros como entidades isoladas, estáveis e estanques, novas propostas e conceitos teórico- 


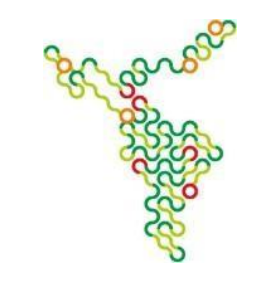

metodológicos começam a se delinear recentemente, a fim de que se estudem os gêneros em situações mais próximas da realidade, sem deixar de considerar sua relação dialógica e outros aspectos sociais. É possível perceber que algumas dessas propostas buscam evidenciar a complexidade das relações linguísticas, discursivas e sociais mediadas pelos gêneros.

Bhatia (2004), por exemplo, entende que as análises do discurso escrito podem se ater ao nível léxico-gramatical ou a outras propriedades textuais, ao uso da linguagem situada em contextos profissionais, institucionais e organizacionais ou, ainda, a um amplo contexto social, nesse caso destacando as relações sociais e identidades, além das forças assimétricas de poder social. O autor propõe que as análises do discurso escrito (que ele também sugere que pode ser visto como texto, gênero, prática profissional ou prática social) ultrapassem o nível da estrutura textual e sugere um modelo que permite uma visão em multiperspectiva sobre o discurso.

Esse modelo possibilitou explorar não apenas a estrutura textual do discurso escrito, mas possibilita ir além do estritamente expresso, considerando como objeto de análise também o contexto de produção dos discursos. Ao considerar o discurso (também) como prática social, o autor favoreceu a que as análises de gênero assumissem uma posição de perspectiva crítica; o que de fato, não poderia ser ignorado por muito mais tempo, haja vista que, desde a declaração de Bakhtin (2004/1979) de que "onde há signo há ideologia", passou-se a vislumbrar a existência de um lado oculto dos enunciados que influencia fortemente no texto (assim como na constituição da sociedade) e que, até então, era um aspecto pouco evidente nas análises.

A partir disso, é possível perceber que a Análise Crítica de Gêneros (ACG), conforme proposto por Bonini (2011), se apresenta como um quadro teóricometodológico que busca entender a dinâmica de funcionamento dos gêneros em sociedade. Isso significa pensar, também, naquilo que influencia os gêneros que circulam socialmente, quais práticas sociais podem impulsionar o surgimento ou o apagamento de um gênero e de que forma os discursos se fazem presentes na constituição genérica. 
Gêneros não surgem do vazio, mas sempre de uma relação de interação com outros gêneros e com outros aspectos do contexto que abrigam esses gêneros. Responsáveis por organizar a comunicação humana, o funcionamento dos gêneros depende tanto de outros gêneros, quanto das estruturas que regulam sua circulação e, por consequência, da forma como os sujeitos estabelecem contato com esses gêneros. Os sujeitos, por sua vez, só têm a possibilidade de conhecer e de dominar a utilização dos gêneros, porque os gêneros contam com suportes físicos e sociais que permitem sua existência e sua circulação em sociedade.

Segundo Bonini (2011), os gêneros se constituem através de relações dialógicas e interdependentes estabelecidas com outros gêneros, com as práticas sociais e discursivas, com as estruturas sociais e com o discurso. Essas relações podem estar restritas ao campo do enunciado ou ampliadas ao âmbito do discurso e das estruturas sociais.

Os sujeitos produtores/receptores envolvidos com o gênero estão envolvidos também em uma série de ações que podem ser relativas às ações de produção, ações de compreensão e ações de textualização. Tais ações dizem respeito àquilo que os sujeitos produtores/receptores precisam acionar quando chamados à produção, textualização e compreensão de um gênero, por exemplo: os conhecimentos sobre o gênero e seus objetivos; o conhecimento de mundo necessário para a textualização ou a identificação do público receptor e do que ele espera compreender desse gênero. Essas ações provocam um resultado a que se pode chamar de prática social do gênero. Entretanto, essas ações de produção, textualização e compreensão do gênero não são levadas em consideração neste trabalho.

De acordo com Lima (2014), o gênero está imerso em práticas sociais que Ihe são inerentes e que determinam sua forma, seu conteúdo, a maneira como os sujeitos o (re)produzem e o compreendem. Essa relação dialógica é um fator constitutivo do gênero, evidenciando que um gênero está sempre conectado a outro, que uma prática discursiva está sempre ligada à outra, interferindo-se e influenciando-se mutuamente. Para entender o gênero sob esse viés, é preciso 


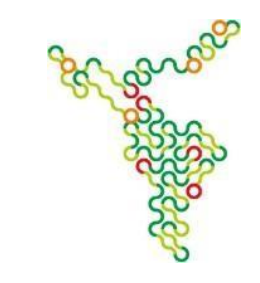

entender como essas relações se estabelecem como fortes influências na formação do gênero e do discurso.

Essa relação de constituição é essencial, pois, em alguns casos, os gêneros nem existiriam se não fossem alguns elementos (o suporte e a mídia, por exemplo), isto é, sem estes, os gêneros não poderiam circular ou seriam completos desconhecidos dos sujeitos. Essa relação de interação entre os gêneros e esses elementos, segundo Bonini (2011), pode ser chamada de relação genérica e podem ocorrer de quatro formas: com o hipergênero, com a mídia, com o sistema de gêneros e com a comunidade discursiva.

O gênero pode se relacionar com um hipergênero, uma espécie de agrupamento de gêneros, onde as produções genéricas simplesmente acontecem em conjunto. Conforme Bonini (2011, p. 691),

essa produção pode ocorrer num agrupamento, que permite formar "uma unidade de interação maior (um grande enunciado)", como o jornal, por exemplo. A mídia, por sua vez, é uma "forma tecnológica material de mediação da interação linguageira, sendo que ela constitui-se de um ou mais suportes e apresenta uma forma característica de organização, produção e recepção" (BONINI, 2011, p. 693). A relação com a mídia é essencial, tendo em vista que, segundo o autor, é a mídia que põe o gênero em circulação e, ainda, organiza os sujeitos produtores/receptores através do cenário espaço-temporal dos gêneros. Ainda segundo o autor, "gêneros e hipergêneros se ajustam às formas de produção e recepção possibilitadas pela mídia". Os gêneros, com suas práticas discursivas, tanto quanto os sujeitos que os produzem/recebem, precisam se ajustar às possibilidades midiáticas para que possam entrar e se manter em circulação social. Por isso, esta é outra das relações que constituem e, de alguma forma, determinam o gênero.

Quanto ao sistema de gêneros, conceito proposto por Bazerman (2006), Bonini (2011, p. 693) declara que "os gêneros podem ser vistos como elementos de uma sequência de práticas e ações sociais [...] [em que] um gênero cria condições para existência de outro”. Já no que se refere à comunidade discursiva, conceito proposto por Swales (1990), "os gêneros em uma comunidade 
discursiva, estão a serviço de uma hierarquia de membros que, juntos, realizam um conjunto de práticas sociais também hierarquizadas" (BONINI, 2011, p. 693). É importante deixar claro que, por uma questão operacional, essas relações genéricas não são tomadas como objeto de análise neste trabalho.

Outro possível nível de análise, conseguinte às relações genéricas, referese às relações do plano do discurso. Para o autor, gêneros são materializações do discurso, assim como as práticas sociais imersas nos gêneros também influenciam os discursos. Por último, aparecem as relações no plano da estrutura social. "As instituições (como a igreja, a economia e a ciência) constituem tanto os discursos quanto as práticas sociais e são, ao mesmo tempo, por esses constituídas" (BONINI, 2011, p. 694).

\section{Análise: práticas identitárias no jornal escolar}

Após a conclusão do processo de produção do jornal escolar, as produções textuais desses participantes foram analisadas com base na ACG (BONINI, 2011). Para a $A C G$, os gêneros precisam ser vistos além do expresso textualmente, pois a produção de um gênero ocorre em consonância com práticas sociais que motivam e impulsionam tal produção. O gênero é apenas um dos componentes de uma relação que envolve não apenas o enunciado em si, mas também a estrutura social que viabiliza a prática e os discursos que influenciam a produção textual e se mostram como um dos componentes mais estruturadores e subliminares do processo.

Busco, na ACG, uma forma de conhecer os gêneros, práticas e discursos nos quais os alunos se engajaram. Assim, a ACG assumiu um aspecto críticosocial que permitiu ir além da análise textual. $O$ objetivo é tentar entender como acontece o engajamento dos alunos nos discursos e práticas e, conforme excerto apresentado neste trabalho, como se enunciam e evidenciam suas identidades através dos gêneros produzidos para o jornal escolar, clivados pela perspectiva histórico-local desses sujeitos aprendizes.

Através desse jornal escolar foi possível encontrar e entender certos aspectos que influenciaram sua produção, assim como que fatores tornaram tal 


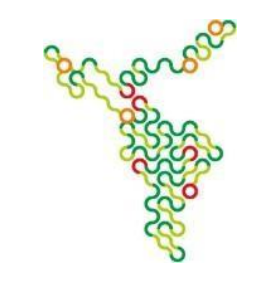

produção possível. Os textos presentes nessas edições deste jornal contemplaram temas que envolveram a realidade local e as práticas sociais com as quais os estudantes-produtores estavam habituados a conviver.

Os temas desses textos foram escolhidos pelos estudantes (que são identificados aqui por nomes fictícios). Sabendo que teriam de dar preferência a temas que mostrassem sua realidade, eles escolheram os seguintes: trabalho na adolescência, futebol como prática saudável e gravidez na adolescência para a edição analisada. A escolha refletiu uma forma de colocar em questão temas que, além de circundar a realidade local, também estão relacionados a questões de relações sociais, de gênero e de poder.

Como ponto de partida para a produção textual, a escolha dos temas permite demonstrar alguns aspectos que envolvem a realidade local e se configuram como uma tentativa de desenvolver uma prática crítica com eles sobre os discursos que circulam em sua comunidade. Essa prática tem seus limites, haja vista que o discurso não é algo que se ensina, mas algo sobre o qual se pode (e deve) refletir à medida que se constrói um pensamento crítico.

O interesse pelo tema 'trabalho na adolescência' surgiu porque o ano de 2012 era, teoricamente, o ano de fechamento do ensino fundamental. Apesar do rápido avanço no ensino fundamental, eles sabiam que seria difícil acompanhar o ensino médio regular e diziam que queriam trabalhar em vez de continuar estudando nos anos seguintes. Eles mostravam medo de voltar a estudar numa sala de aula regular (e com razão), talvez por saberem que salas de aula regulares são diferentes das de correção de fluxo, a começar pelo número diferente de disciplinas (quatro disciplinas na correção de fluxo contra 13 no primeiro ano do ensino médio).

A prática de "conseguir um emprego depois da escola" ou de "já que você não estuda, precisa trabalhar" atinge, especialmente, esses estudantes. Sabendo que antes dos 16 anos eles não poderiam trabalhar a não ser se vinculados a um programa de menor aprendiz, três alunas (Gabriela, Natália e Olga) sugeriram esse tema e acharam que ele seria também de interesse da turma e de outros colegas formandos. Elas trouxeram, então, informações sobre as possibilidades de 
trabalho para os estudantes dos anos finais do ensino fundamental, ou para os menores de 16 anos interessados em trabalhar. Percebe-se que para esses estudantes a necessidade de trabalhar é muito mais uma questão de sobrevivência que de aquisição de independência financeira. Aliando isso à dificuldade com a reintegração ao ensino regular, a procura pelo primeiro emprego se faz presente entre suas preocupações.

A produção desta edição ainda serviu como um teste para alguns dos estudantes que, apesar de estarem interessados no projeto, não entendiam que tipos de decisão precisavam tomar, quanto aos textos ou às tarefas a serem cumpridas. Por isso, o estudante Alexandre, que gostava demais de futebol, logo mostrou interesse pelo tema. No entanto, como ele sabia que o tema precisava estar relacionado à realidade dele ou da turma, pediu ajuda para definir sobre qual assunto, dentro desse tema, ele poderia escrever. Após uma conversa sobre os seus interesses, percebi que ele gostava de atividade física, mas não tinha condições financeiras de frequentar qualquer lugar que oferecesse uma atividade desse tipo. Após conversarmos sobre o assunto, surgiu a ideia de que o futebol praticado no pátio do condomínio também é uma atividade saudável e que muitos de seus colegas, inclusive ele mesmo, nunca tinham pensado sobre isso. Não é difícil de perceber que o texto de Alexandre reproduz um discurso de vida saudável que enaltece aqueles que se "mantêm em forma" e condena os sujeitos

avessos a essa prática. $O$ tema de sua produção textual, então, se tornou a prática de futebol como atividade física saudável. A situação desses jovens que, mesmo morando em um bairro periférico, convivem com um alto padrão de vida que uma cidade a que eles vivem pode oferecer, tem se tornado difícil. A diversão do fim de semana desses e de muitos outros jovens é passear no shopping, um lugar inacessível para muitos. Depois da mudança para o Condomínio ${ }^{1}$, um condomínio novo e até bem localizado, tendo em vista a distância do centro da cidade, sua condição financeira continua a mesma de quando moravam em casas pequenas em bairros um pouco mais distantes. Eles têm acesso ao que a sociedade oferece àqueles que dispõem de moeda de troca, mas muitos deles não 


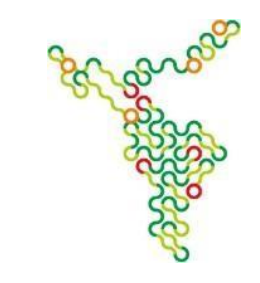

têm. Assim, ao falar do futebol como uma prática saudável, Alexandre sabe das precárias condições de saúde dele e de muitos de seus colegas, mas ainda assim, manteve em seu texto a "recomendação" de procurar orientação de um médico e de um profissional de educação física antes de começar a praticar uma atividade física (informação que constava do texto-fonte). Em seu texto, Alexandre quis exaltar que a prática do futebol no pátio do condomínio é uma opção para aqueles que não podem pagar por uma academia, mas "esqueceu-se" de que a consulta médica é tão cara quanto uma mensalidade de academia. Esses jovens precisam aprender a conviver em uma sociedade que não faz questão da sua presença, que mantém seus atrativos visíveis a todos, mas acessíveis a poucos.

Outro tema levantado pela turma, e que entrou nessa primeira edição, foi o da gravidez na

adolescência. A gravidez era um tema conhecido, pois muitos já namoravam e não gostariam de passar pela mesma situação de uma das colegas que teve um filho aos 14 anos de idade. $O$ filho de Camila estava com quase dois anos. Inclusive, um dos textos dessa edição foi escrito por Camila, no qual ela conta sua história desde a gravidez até o nascimento do bebê. Já o texto sobre a gravidez na adolescência foi escrito por outro estudante, Lauro, que namorava há algum tempo e, por isso, apresentou certo interesse pelo assunto.

Foi possível perceber que o tema da gravidez, apesar de conhecido, é um tabu para esses jovens, mesmo para aquela que já é mãe. Eles têm vergonha de falar no assunto e talvez, pela falta de conversa com alguém mais experiente, seja proeminente o risco de uma ou outra gravidez na adolescência. $O$ discurso machista é latente nesses jovens, pois os meninos se mostravam mais abertos a falar sobre o assunto, tendo em vista que um garoto escolheu falar sobre o tema. Já as meninas nem quiseram falar muito sobre e, quando perguntadas sobre sexo, apenas riam ou nada respondiam. Mesmo o aluno Lauro, que escreveu sobre o tema, apresentou dificuldade em pesquisar sobre 0 assunto ou em fazer perguntas quando tinha dúvidas. A fase inicial da produção foi polêmica, mas o resultado foi condizente com um trabalho árduo de quebra do discurso proveniente de uma sociedade machista. Com a publicação da história de Camila, os outros 


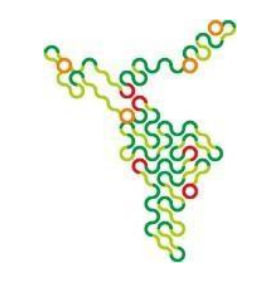

alunos entenderam um pouco mais o tema e, inclusive, estabeleceram alguma empatia com a colega-mãe.

Apesar de se interessar pelo assunto, de mostrar vontade de saber mais sobre as formas de evitar uma gravidez ou de saber o que fazer quando (ou se) acontecer uma gravidez, Lauro teve dificuldade em deixar seu texto mais próximo da realidade da turma. É compreensível, tendo em vista a complexidade do assunto e a inexperiência com este. Ainda assim, escrever sobre gravidez na fase da adolescência serviu para que a turma parasse para perceber as dificuldades que a colega Camila enfrentava diariamente. $O$ texto mostrou que a gravidez não é como "brincar de casinha", mas como estavam na adolescência, informações sérias não são levadas tão a cabo quanto deveriam. Além disso, o acesso à informação nem sempre é suficiente. A prova disso é que, apesar de expor as dificuldades em seu texto, Camila engravidou novamente. Ao final de 2013, ela estava grávida de seu segundo filho.

No texto de Camila é possível perceber que ela replica o discurso de algumas instituições, como o da igreja, por exemplo. Apesar do desespero em saber que estava grávida, em nenhum momento Camila pensou em não ter o seu "pequeno anjo". Talvez seu pensamento tenha sido esse, mas por ser cristã nem tocou no assunto (ao menos, não no texto). Deve acreditar ser vergonhoso ou pecado: "só Ele dá e só Ele pode tirar".

Camila replica bordões de comerciais que recomendam 0 uso de camisinha: "sexo é vida"; "sem camisinha não dá"; "proteja-se". No entanto, essas mensagens, veiculadas diariamente, não foram suficientes para que ela e o parceiro usassem a camisinha nem na primeira, nem na segunda gravidez. Além disso, toda a dor sofrida com a notícia da primeira gravidez não serviu como experiência para evitar a segunda, aos 16 anos.

\section{Considerações Finais}

Sob o propósito de analisar as características evidenciadas nos textos produzidos por estudantes de uma turma de correção de fluxo de uma escola do 


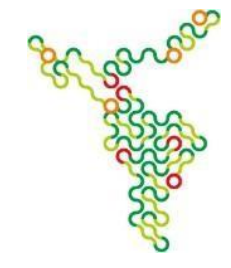

ensino fundamental de Tubarão/SC, este trabalho evidencia as práticas identitárias desses estudantes e, para além disso, mostra como os jovens em questão são influenciados por discursos que os colocam abaixo das expectativas sociais.

Mesmo convivendo com discursos que controlam e, muitas vezes, anulam pensamentos ou modos de ser, esses estudantes mostram em seus textos que aquilo que as pessoas dizem sobre eles (o discurso como prática social) pode ser discutido, combatido e modificado. Seus textos evidenciam que aquelas características identitárias/representações sociais que lhes foram atribuídas não precisam ser tomadas como absolutamente verdadeiras, estáticas e/ou definitivas. Por conta disso, modificaram alguns de seus comportamentos e isso interferiu nos caminhos que tomaram durante e ao final do ano letivo. Mas é importante salientar, o fato de esses jovens terem demonstrado que suas identidades podem ser constituídas de maneira diferente daquela que a sociedade determina, não significa que tenham tomado consciência sobre a origem dessa constituição. Entretanto, através de seu comportamento, evidenciaram que, de alguma forma, podem assumir uma posição quanto a esses fatores constitutivos de suas identidades.

Um exemplo dessa primeira mudança de prática identitária é a própria produção do jornal escolar. Classificada pela escola tal como o ato de "tirar leite de pedra", esses estudantes mostraram que são mais que os "rejeitados" que "não tem mais jeito". Com a publicação do jornal, esses estudantes exerceram mudanças em suas identidades, mostrando para os colegas e para os professores que, apesar do estereótipo de rejeitados, eles eram capazes de produzir, modificando a prática escolar. Outras modificações identitárias relevantes estão relacionadas às práticas de trabalhar ou de estudar. No início do ano letivo, a maioria da turma dizia que este seria seu último ano escolar, que no ano seguinte não sabiam o que fariam porque não tinham vontade de fazer nada. Antes mesmo do fim do ano letivo isso foi mudando: após a publicação do texto sobre programas de menor aprendiz, alguns desses estudantes procuraram por esses programas e ingressaram no mercado de trabalho. E, ao final do ano, após o término do 
ensino fundamental, ao menos metade da turma matriculou-se no ensino médio para continuar estudando no ano seguinte. Essas são importantes mudanças sociais que se evidenciaram nas produções para o jornal escolar. Pequenos ajustes no discurso que circulava nos textos produzidos pelos estudantes levaram à mudança da prática social e, consequentemente, a outras práticas identitárias.

\section{Referências}

BAKHTIN, M. M. Marxismo e filosofia da linguagem: problemas fundamentais do método sociológico na ciência da linguagem. Trad. de Michel Lahud, Yara Frateschi Vieira. São Paulo: Hucitec, 2004/1979.

BHATIA, V. K. Worlds of written discourse: a genre-based view. London; Continuum, 2004.

BAZERMAN, C. Gêneros textuais, tipificação e interação. Trad. de Judith Chambliss Hoffnagel. São Paulo: Cortez, 2006.

BONINI, A. Mídia, suporte e hipergênero: os gêneros textuais e suas relações. Revista Brasileira de Linguística Aplicada, Belo Horizonte, v. 11, n. 3, p. 679704, 2011.

LIMA, V. W. A prática social no jornal escolar: estudo do ponto de vista da análise crítica de gênero. 2014. Tese (Doutorado em Ciências da Linguagem) Universidade do Sul de Santa Catarina, Tubarão. 